\title{
EDITORIAL Solo sexo. Solo fallo
}

\author{
Mariana Gómez"
}

Universidad Nacional de Córdoba

Los primeros fríos de mayo llegaron con la XII Edición del Ciclo de Cine y Psicoanálisis de la Universidad Nacional de Córdoba. Esta vez la propuesta nos llevó a interrogarnos sobre el sintagma Solo Sexo. ¿Solo sexo, sin amor? ¿Solamente sexo? ¿Sexo en soledad? Su equivocidad no tardó en resonar. Y sobre estas posibilidades y algunas más, se trabajó, se pensó, se cuestionó. Durante los cuatro martes de mayo, mes de revoluciones y revueltas, si las hay, alrededor de 500 personas se encontraron en el Pabellón Argentina para escuchar a psicoanalistas y representantes de la cultura cordobesa, hablar de sexo. De lo que siempre fracasa, como lo dijera Jacques Lacan en aquella oportunidad en la Universidad de Yale.

Las preguntas sobre los lazos sexuales, la elección del partenaire sexual, la pornografía, el lugar de la tecnología y el sexo online, intentaron ser respondidas a partir del análisis de cuatro películas elegidas por el equipo del Ciclo, luego de varios meses de trabajo y discusión. Así, pudimos dejarnos enseñar por La chica danesa (UK, 2015), El tercero (Córdoba, 2014), Men, woman and children (EEUU, 2014) y la serie Master of sex (EEUU, 2013). Aun reconociendo lo imposible de saber, de nombrar, de representar de la relación sexual que, como sabemos, para Lacan, no existe.

Decía Lacan en la mencionada universidad que todo lo que tiene que ver con el sexo está siempre mal hecho (est toujours raté). Era para él la base y el principio mismo de la idea de fiasco. El fallo (ratage) mismo, señalaba, puede ser definido como lo que es sexual en todo acto humano. Por eso hay tantos actos fallidos. De allí que Freud indicara que un acto fallido siempre tiene algo que ver con el sexo. El acto fallido por excelencia es precisamente el acto sexual. Uno de los dos es siempre insatisfecho y es eso de lo que siempre hablan las personas (Lacan, 1975).).

Pero además, la cuestión del sexo no pasa por el destino fijado en lo real del cuerpo y por eso Lacan plan- teará la cuestión en términos de sexuación, que supone posiciones de goce diferentes en donde un sujeto pueda ubicarse y en donde no todo es fálico.

Y si bien es necesario pasar por el discurso del Otro para realizar el proceso de la sexuación, no todo es producto del Otro, hay algo que además implica puramente al sujeto y a su acto. A la propia elección de goce. Al propio modo de gozar.

Lacan deconstruye derridianamente el dualismo cartesiano de la sustancia pensante y la extensa, para proponer una sustancia gozante. Al cuerpo lo definirá por lo que se goza, en donde la diferencia sexual es solo diferencia de goces. Y aunque la sexuación ponga en juego a las identificaciones, hay algo en ella que no puede ser reducido a una identificación.

Por eso, temas como la identidad de género, las compulsiones, la pornografía, la prostitución, el autoerotismo, el goce perverso, fueron lanzados en las páginas de este número recuperando varios de los trabajos presentados en ocasión del Ciclo de Cine y sumando otros que, creemos, enriquecen la perspectiva y ponen al trabajo y a la discusión el tema que nos convocó.

El psicoanálisis cambia y es necesario estar advertidos de lo nuevo. Si el psicoanálisis fue inventado por Freud bajo la piedra de la represión de la sexualidad, hoy en el siglo XXI nos encontramos con su mostración desinhibida, de la mano de la industria y liderando los cambios tecnológicos de este sector del capitalismo. Entonces, preguntarnos sobre uno de los motores que mueven al mundo -el otro es la guerra, lo sabemos- ha respondido a un deseo, un deseo de saber. Preguntarnos sobre los modos, sobre las diferencias, las singularidades y los derechos del goce y dejar que la escritura permita bordear eso imposible de decir. Dejar que algo cese de no escribirse. Aunque, como dijo Auster, lo más difícil es escribir sobre sexo.

Este número nos trae trabajos que hacen olvidar cualquier frío de otoño. Número este, el de Ética \& Cine,

margo@ffyh.unc.edu.ar 
que nace al calor del mes de las revoluciones y de las revueltas. Mayo Francés, Revolución de Mayo, Cordobazo... nos evocan, indefectiblemente, a la revolución que viene atravesando al mundo desde hace más de un siglo, la sexual y de la mano de otra no menor, la del psicoanálisis. Los invito, queridos lectores, a transitarlo.

\section{Referencias}

Lacan, J. (1975), Yale University, Kanzer Seminar. Tomado de la revista Scilicet, 6/7, 1975 Paris: Eds. du Seuil.

Lacan, J. (1995), “Aun” en El seminario, Libro 20. Buenos Aires: Paidós.

Miller, J.-A. (2014), “El inconsciente y el cuerpo hablante”. Presentación del tema del X Congreso de la AMP en Río de Janeiro. 